\title{
Estimating the density of honey bee (Apis mellifera) colonies using trapped drones: area sampled and drone mating flight distance
}

\author{
Patsavee Utaipanon, Michael J. Holmes, Nadine C. Chapman, Benjamin P. Oldroyd \\ Behaviour and Genetics of Social Insects Laboratory, Ecology and Evolution, University of Sydney, Macleay Building \\ A12, Sydney, NSW 2006, Australia
}

Received 12 December 2018 - Revised 20 April 2019 - Accepted 24 June 2019

\begin{abstract}
Reliable information on Western honey bee colony density can be important in a variety of contexts including biosecurity responses, determining the sufficiency of pollinators in an agroecosystem and in determining the impacts of feral honey bees on ecosystems. Indirect methods for estimating colony density based on genetic analysis of sampled males are more feasible and cost efficient than direct observation in the field. Microsatellite genotypes of drones caught using Williams drone trap are used to identify the number of colonies (queens) that contributed drones to a mating lek. From the number of colonies, the density of colonies can be estimated based on assumptions about the area from which drones are drawn. This requires reliable estimates of drone flight distance. We estimated average minimum flight distance of drones from feral colonies along two 7-km transects in Southern NSW, Australia. We found that drones from feral colonies flew at least $3.5 \mathrm{~km}$ to drone traps. We then determined that the maximum distance that drones flew from a focal colony to a trap was $3.75 \mathrm{~km}$. We conclude that a drone trap samples an area of $44 \mathrm{~km}^{2}$, and that this area should be used to convert estimated colony numbers to colony densities. This area is much greater than has been previously assumed. The densities of honey bee colonies in Grong Grong and Currawarna, NSW, are 1.38-2.73 and 1.31-3.06 colonies $/ \mathrm{km}^{2}$ respectively.
\end{abstract}

\section{drone flight range / colony density / mating behaviour / feral honey bee}

\section{INTRODUCTION}

The Western honey bee (Apis mellifera) was originally native to Africa, Europe, and the Middle East, but has subsequently been spread throughout the world as a consequence of deliberate introduction (Ruttner 1988; Winston 1992; Moritz et al. 2005). A. mellifera (hereafter 'honey bee') can now be found in most parts of the world

Electronic supplementary material The online version of this article (https://doi.org/10.1007/s13592-019-00671-2) contains supplementary material, which is available to authorized users.

Corresponding author: P. Utaipanon, puta5072@uni.sydney.edu.au

Manuscript editor: David Tarpy in wild, feral, or managed populations (Paton 1996; Moritz et al. 2007). Honey bees are widely used as generalist pollinators in agriculture and form the basis of the honey and beeswax industries (Crane 1990). Even in their introduced range, feral honey bees can provide important ecosystem services by pollinating native and crop plants (e.g. Dick 2001; Gross 2001; Klein et al. 2003; Klein et al. 2007; Cunningham et al. 2016).

Robust information about feral and wild honey bee colony densities is important in several contexts (Utaipanon et al. 2019). First, about $1 / 3$ of crops benefit from insect pollination, the majority of which is provided by honey bees (Klein et al. 2007), including the Asian species. Some growers rent large numbers of colonies at considerable expense, assuming that the pollination service 
provided by feral honey bees and native pollinators is inadequate. Other growers are reluctant to rent colonies, assuming that the density of wild pollinators is sufficient to provide adequate pollination, or that the leasing cost does not warrant the benefits of increased production and quality (Cunningham et al. 2002). Either way, the decision about whether to invest in paid pollination is sometimes based on limited information and as a consequence a grower may suffer reduced yields and quality, or incur unnecessary expenditure on renting colonies.

Second, honey bee colonies are vulnerable to a variety of exotic parasites and pathogens (e.g. Morse and Nowogrodzki 1990; Bailey and Ball 1991). When a new exotic pathogen or parasite is first detected, it is often desirable to mount a biosecurity response in an effort to contain or eliminate the threat to domestic honey bee populations, or to retain access to international markets for bees and bee products. The success of a biosecurity response depends in part on an understanding of the density of colonies in the area in which the biosecurity threat is first detected. If the density of colonies is very high, and most of them are wild, the likelihood of finding and then eradicating or treating every colony is slim. On the other hand, if wild colonies are rare or absent, mounting a biosecurity response may be justified.

Third, in some areas where honey bees have been introduced, feral populations may have negative effects on native animals and plants (reviewed in Paton 1996; Goulson 2003; Hanley et al. 2008). Potential negative effects include competition with native insects, birds, and mammals for floral resources (Gross 2001; Hansen et al. 2002); competition with native mammals and birds for nest sites in tree hollows (Saunders et al. 1982; Oldroyd et al. 1994; Wood and Wallis 1998); pollination of exotic weed species, thereby enhancing their weediness (Butz Huryn and Henrik 1995; Gross and Mackay 1998; Simpson et al. 2005); and inadequate or inappropriate pollination of native plant species (Paton 1993; Gross and Mackay 1998). Understanding the extent and potential significance of these negative effects depends in part on having good estimates of the density of feral honey bee colonies. If the density of feral colonies is low, their presence may be of limited importance. If the density is very high in an area of high conservation value, there may be a case for implementing management strategies for reducing feral colony numbers. In contrast, there are occasional calls to ban domestic honey bee colonies from areas of high conservation value (e.g. Spira 2001; Magrach et al. 2017), but the case for such action may be diminished if there are already large numbers of wild colonies in the area.

The foregoing shows that reliable information about honey bee colony density can be crucial in contexts as diverse as enhancing crop yields, managing a potential environmental stressor, and mounting an effective biosecurity response. Unfortunately, honey bee nests are hard to find in the field because they are typically built in lofty locations in tree hollows and the like. For this reason, it is almost impossible to assess colony densities over a large area such as a national park, horticultural region, or area with inaccessible land by systematic searches for colonies (Wenner 1989; Oldroyd et al. 1997; Seeley 2016). The most feasible method to estimate honey bee colony density without manual surveys or bee lining (a laborious process in which foraging bees are caught and traced back to their nest, Wenner 1989; Seeley 2016) is to infer number of colonies in an area from samples of drones. Drone honey bees become sexually mature at about 2 weeks of age (Currie 1987; Page and Peng 2001). When they are about 3 weeks old, they commence daily mating flights between about 14:00 and 17:00 (The exact time is location- and season-specific, Oertel 1956; Taber 1964; Rinderer et al. 1993). After leaving their colony, drones fly to specific locations in the landscape known as drone congregation areas (DCAs) (Ruttner 1974; Ruttner 1976). Mating takes place on the wing at the DCA (Loper et al. 1987; Koeniger 1990; Winston 1991), facilitating outbreeding (Baudry et al. 1998; Koeniger et al. 2005). Drones follow specific routes from their colony to the DCA, typically following linear features of the landscape, such as tree lines, watercourses, or roads (Loper et al. 1992).

Drones can be conveniently sampled at DCAs, or the flyways leading to DCAs, using a Williams drone trap (Williams 1987; Moritz et al. 2007; Jaffé et al. 2010; Arundel et al. 2012; Moritz 
et al. 2013; Hinson et al. 2015). A Williams drone trap comprises a tapered tulle cylinder $1.5 \mathrm{~m}$ long and $500 \mathrm{~mm}$ wide at its base (Williams 1987). Lures fashioned from blackened cigarette filters and impregnated with the queen's sex pheromone 9-oxo-2-decanoic acid (9-ODA) attract mature drones over short $(100 \mathrm{~m})$ distances (Butler et al. 1962; Gary 1962; Brockmann et al. 2006). The trap is raised aloft in a likely looking spot (an open area surrounded or flanked by trees) using a tethered weather balloon filled with helium. Drones approach the lures and attempt to mate with them, but realise their mistake at the last moment, fly upwards, and enter the trap (see video in supplementary material). By this means, it is often possible to capture hundreds of drones in $30 \mathrm{~min}$.

After obtaining a sample of drones in the field, the drones are genotyped at 6-10 microsatellite loci (Moritz et al. 2007; Hinson et al. 2015). The multilocus genotypes are then classified into groups of brothers based on maximum likelihood (Wang 2004; Utaipanon et al. 2019). Each group of brothers and singleton drones is assumed to come from a different colony. To obtain an estimate of colony density, it is necessary to divide the estimated number of colonies represented in the sample by the area from which the drones are drawn. In the literature, the area sampled is assumed to be $2.54 \mathrm{~km}^{2}$ (Moritz et al. 2007; Jaffé et al. 2010). This estimate is based on a single study of the distance that drones fly from their colony on mating flights (Taylor and Rowell 1988). However, the Taylor and Rowell study was based on capturing marked drones at a known DCA. The study did not extend beyond the identified DCA to find the maximum drone mating flight range. Therefore, the true area sampled by a drone trap is likely to be significantly greater than $2.54 \mathrm{~km}^{2}$.

The area over which a drone trap samples drones is crucial to the accurate estimation of colony density. The area sampled is approximated by $\pi r^{2}$ where $r$ is the maximum flight range of a drone from his colony on a mating flight. Since the area sampled scales as $r^{2}$, small changes in $r$ have a large effect on the area and estimates of colony density. Therefore, to obtain reasonable estimates of the density of colonies in a landscape, it is important to obtain robust estimates of the area sampled by a drone trap (Arundel et al.
2013). This issue is complicated by the fact that the presence of a trap in the environment may change drone behaviour. In particular, the presence of large amounts of synthetic queen pheromone may attract drones from an unnaturally large area, which may be asymmetrical depending on wind direction.

Here we report (1) the distribution and relatedness of drones captured at 500-m intervals along two 7-km transects in southern NSW, Australia, and (2) the distance from a focal colony over which drones can be captured. From these data, we provide estimates of drone mating flight distance, the number of colonies sampled at a trap location, and the area from which a drone trap samples colonies.

\section{METHODS}

\subsection{Experiment 1: Drone flight distances of multiple feral colonies of unknown location}

\subsubsection{Study location and transect design}

We sampled males using a Williams drone trap along two 7-km transects parallel to Bundidgerry Creek and the Murrumbidgee River, in Grong Grong and Currawarna, NSW, Australia, respectively. The centre of transect A was located on Old Wagga Road at $34^{\circ} 45^{\prime} 42.53^{\prime \prime} \mathrm{S}, 146^{\circ} 41^{\prime} 37.87^{\prime \prime}$ E. Transect B was $40 \mathrm{~km}$ from transect A, on a roughly linear stretch of Old Narrandera and Ganmurra Roads. The centre of this transect was at $35^{\circ} 0^{\prime} 52.60^{\prime \prime} \mathrm{S}, 147^{\circ} 4^{\prime} 43.50^{\prime \prime} \mathrm{E}$. We established sampling sites every $500 \mathrm{~m}$ along the two transects based on two criteria: (1) the sampling site needed to be an area of at least 4-m radius that was free from tree branches and (2) at least one side of the space had to be bounded by trees (Figure 1). The first transect was sampled in November-December 2017, and the second in January-February 2018. This period encompasses late spring and summer in NSW. Drones are present in colonies in high numbers at this time of year.

The area sampled was flat agricultural land, used for mixed farming, and mostly cleared of native vegetation during the late nineteenth century. Remnant Eucalyptus forest, mostly river red 


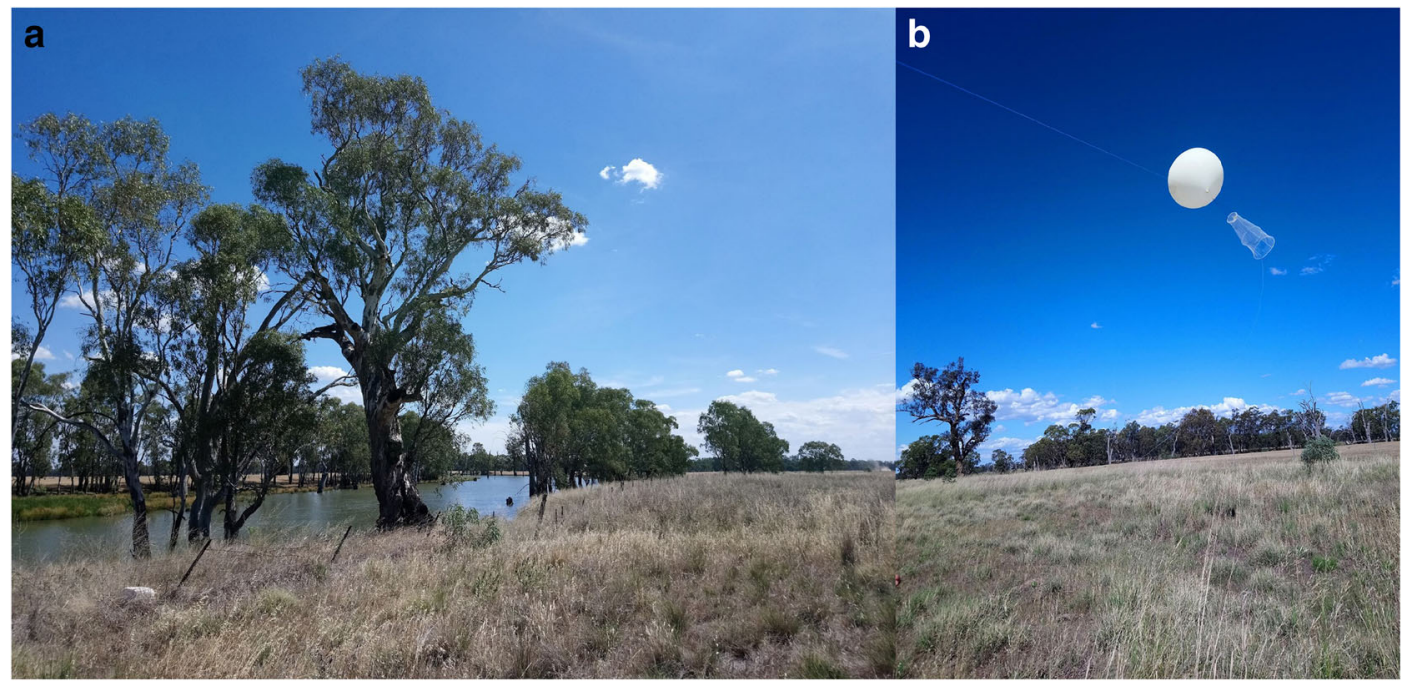

Figure 1. a Typical sites used for drone trapping in experiment 1. Note that there are features that would encourage the formation of high-density DCAs. b Drone trapping in experiment 1 using a Williams drone trap.

gum (Eucalyptus camaldulensis), lines the creeks, rivers, and road sides. These trees contain numerous hollows suitable for nesting by feral honey bees, and provide a significant food source that complements that available from weedy species such as Patterson's curse (Echium plantagineum) and fireweed (Senecio madagascariensis) and crops such as canola (Brassica napus) and sunflower (Helianthus annuus ) that are grown in the fields.

\subsubsection{Drone sampling}

We trapped drones daily between 14:30 and 17:30 (GMT+11), whenever the weather was suitable (i.e. not raining and low to moderate windspeeds). Empirically, drones were flying and could be caught between these hours. Most mature honey bee colonies have many hundreds of mature drones (Allen 1963; Szabo 1995). Nonetheless we avoided sampling adjacent sites on consecutive days to avoid depleting the drone population in any particular colony. We aimed to capture 100-200 drones per site. If we caught less than 100 drones on an afternoon, which was typically the case when the weather was cloudy or windy, we resampled the site the following day. If the conditions were excellent for drone trapping, but we had difficulty in capturing 100 drones, we assumed that the site was not suitable for drone trapping, or that the number of feral colonies in flying range was low.

\subsubsection{Microsatellite analysis}

We extracted DNA from collected drones using the Chelex protocol (Walsh et al. 1991). We then used nine unlinked polymorphic microsatellite markers to obtain a multilocus genotype for each drone. Microsatellite markers (A8, A24, A29, A35, A79, A88, A107, A113, B124; Solignac et al. 2003; Solignac et al. 2007) were amplified in two multiplexes, each locus identifiable by a different fluorescent label and its size range. PCR products were electrophoresed using a $3130 \mathrm{xl}$ genetic analyser (Applied Biosystems ${ }^{\mathrm{TM}}$ ). Drone genotypes were then determined using GENEMAPPER 4.0 software.

\subsubsection{Colony and queen identification}

We used COLONY 2.0.6.4 to assign drones to brother groups and to reconstruct the genotypes of their diploid queen mothers (Wang 2004; Wang 2013). We specified a haplodiploid mating system and assumed that all drones were queen laid, (i.e. that the number of worker-laid males was negligible). The number of reconstructed queens was assumed to equal the number of colonies sampled 
at each trap site. Reconstructed families with fewer than three members may not be brothers because they are grouped with low likelihood. We therefore present our analyses based on data sets where all families with $<3$ drones were discarded.

\subsubsection{Inferred family selection}

This study was based on a linear transect, and we sampled drones from colonies of unknown location. Families that were absent at most sites and uncommon at the sites where they were present were likely to be derived from colonies distant from the transect. Such colonies would provide unreliable information about flight range along the linear transect (Figure 2). Therefore, we selected only those colonies whose drones were present at high frequency at least one site. Such colonies were likely to be close to the transect, so that their flight range would not be underestimated because they were distant from the transect. To do this, we ranked all colonies according to the number of captured drones per colony and selected only those colonies above the 90th percentile. All other colonies were discarded from the data set.

\subsubsection{Drone flight range estimation}

Since a colony could be located at one end (colony A in Figure 2) or located at a substantial distance from the transect (colony B in Figure 2), we assumed that the colony whose drones were sampled at the most sites provided the best estimate of maximum flight range (colony $\mathrm{C}$ in Figure 2). We therefore tabulated the number of males from each family at each sampling site in an Excel spreadsheet (Supplementary table S1), each column representing one of the 15 sites per transect, and each row a family of brothers (= a colony). For each colony, we determined the maximum distance between a pair of sites in which brother drones were present. We then identified the colony with the greatest distance between sampling sites, assuming that such a colony was at or near the middle transect (Figure 2). The distance over which drones fly from their colonies

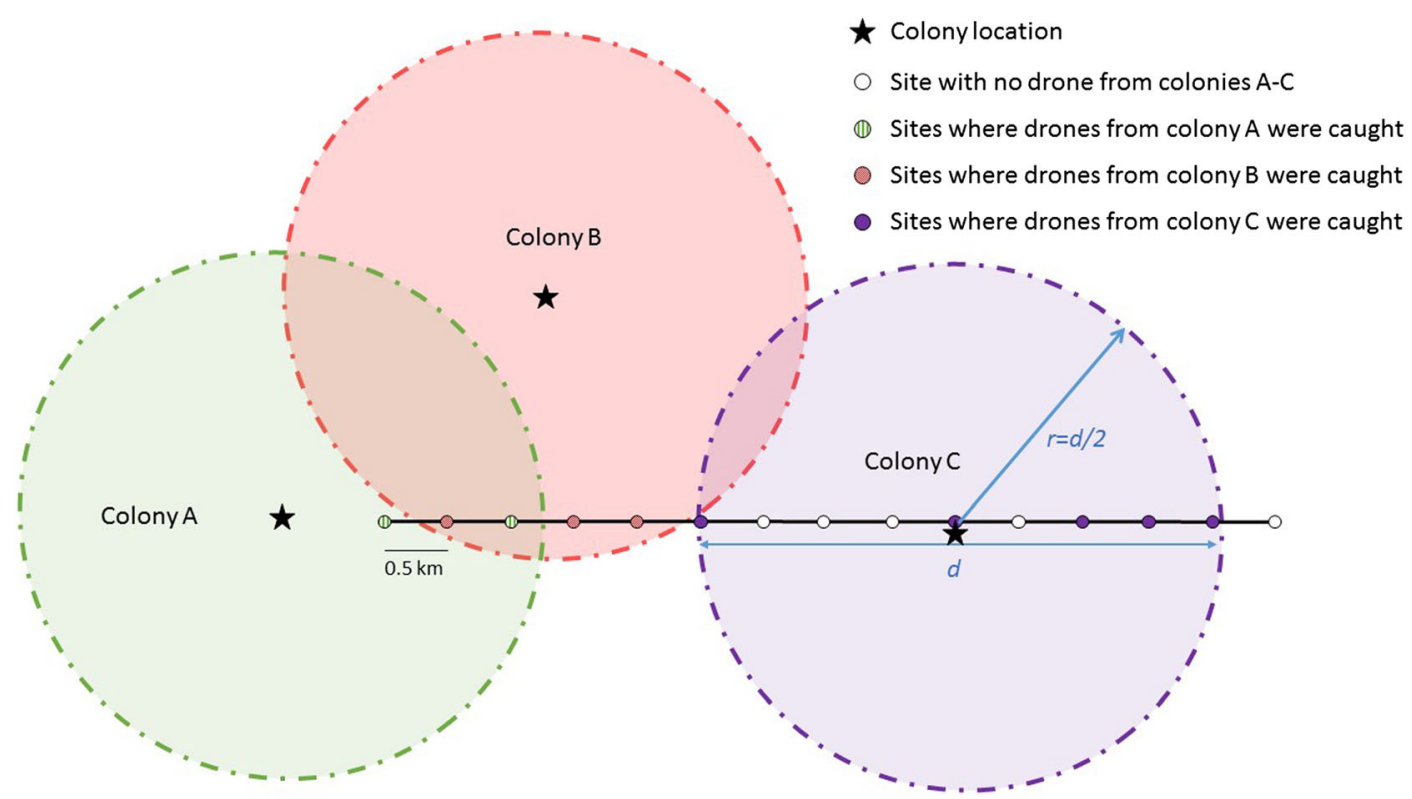

Figure 2. Hypothetical illustration of drone flight distances from 3 colonies (A, B, and C) along a linear 7-km transect. Colony A is located close to the transect but at one end. Drone flight distance of this colony is also underestimated as $0.5 \mathrm{~km}$ (i.e. half of the observed maximum distance between sites where its drones were sampled. Colony $\mathrm{B}$ is situated $1.5 \mathrm{~km}$ from the transect, and its drone fight range is also underestimated as $1 \mathrm{~km}$. Colony $\mathrm{C}$ is located on the transect. Its drone flight range, $r$, is accurately estimated as $d / 2=2 \mathrm{~km}$. 
to a drone trap $(r)$ was then estimated as half of the maximum distance between sites represented by this colony ( $d$ in Figure 2).

\subsection{Experiment 2: Flight range of drones from a focal colony}

In this experiment, we established a single drone-producing colony and trapped drones from this colony at $250-\mathrm{m}$ intervals in two linear directions. This experiment was complementary to experiment 1 in that it provided an independent estimate of drone flight range.

\subsubsection{Colony preparation}

This study was begun in early August 2018 in winter but after the winter solstice, when A. mellifera colonies are eager to rapidly increase brood production if provided with the right food. We selected the strongest colony at our apiary at the University of Sydney, and stimulated it to produce drones in large numbers by feeding supplementary pollen within the colony, and by providing four combs with brood cells of the size used by honey bees to rear drones. The apiary is located near the coast in an urban area where the climate is relatively mild, and there are numerous flowering plants both on campus and in surrounding suburbs that provide early stimulus for brood rearing.

\subsubsection{Experimental location}

The experimental colony responded well to stimulation and carried an estimated 5000 mature drones by the start of our experiment on September 17, 2018. On that day, we transported the colony $265 \mathrm{~km}$ over the Blue Mountains to Lyndhurst, NSW ( $33^{\circ} 43^{\prime} 57.5^{\prime \prime}$ $\left.\mathrm{S}, 149^{\circ} 01^{\prime} 19.4^{\prime \prime} \mathrm{E}\right)$. Due to the cooler climate (elevation $670 \mathrm{~m}$ ) and lack of artificial nutritional stimulation, the local colonies in Lyndhurst were at least 1 month behind our experimental colony in their brood rearing, and most carried few or no sexually mature drones. We left the colony in the study area for a week, so that its drones had time to explore the area around their colony, and perform normal mating flights. After 1 week, we opened the colony and marked drones with a thoracic paint mark (Uni POSCA marker pens, Japan) with 5 different colours (Figure 3). We continued to mark drones each morning prior to drone trapping during the normal drone flight time (around 14:00-16:00 GMT+10). We paint

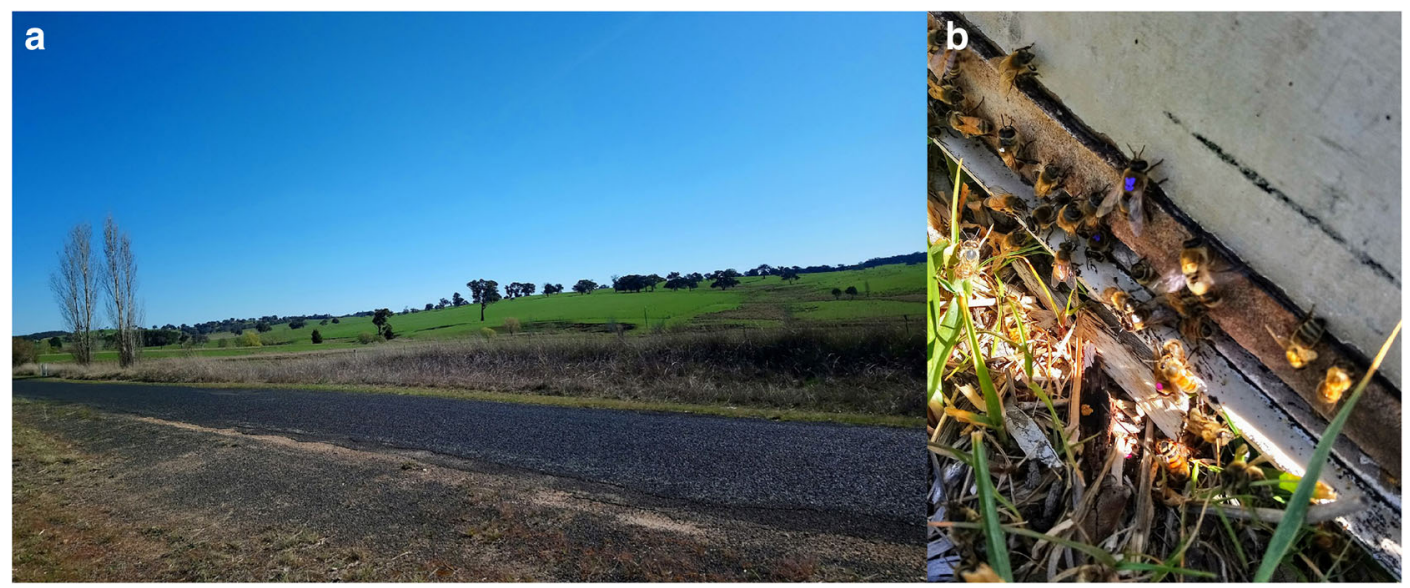

Figure 3. a The landscape of experiment 2. There were no obvious landscape features that would encourage the formation of DCAs. b Paint-marked drones leaving the focal colony for a mating flight. 
marked 6209 drones during this experiment over the course of 28 days.

\subsubsection{Bidirectional transect sampling}

We sampled drones using a Williams drone trap as above. We sampled every 250 or $500 \mathrm{~m}$ along Garland Road in two directions from the experimental colony from 13:00 to $15: 30$ $(\mathrm{GMT}+11)$, which was the local drone flight time observed in the area during our experiment. The first site was $250 \mathrm{~m}$ from the hive in a southerly direction. As soon as a marked drone was caught, we moved to a site $500 \mathrm{~m}$ north of the colony, then to $1000 \mathrm{~m}$ south of the colony and so on, in a pendulum fashion, until no marked drones were caught (Figure 4). We released marked drones after trapping, but photographed the paint mark to ensure that each trapped male was an independent observation (To our knowledge, we did not resample any drone.) The landscape along the transect was gently undulating, and used for mixed farming, particularly cattle grazing. Tree cover was sparse but regular (Figure 3) providing limited opportunities for drones to selforganise into congregation areas. We defined the end of the flight range by the distance at which no further marked drones were caught, but more than 30 unmarked drones were caught. The presence of unmarked drones at the distant sites showed that the conditions for drone flight and capture were satisfactory.

\subsubsection{Genetic analysis}

We confirmed absence of drones from the focal colony at both ends of the transect using microsatellite markers - that is we verified genetically that none of the unmarked drones were from the focal colony. To obtain a reference genotype for the mother queen, we collected 24 drone pupa directly from the colony. We then extracted DNA and amplified microsatellite markers of the reference pupa using nine unlinked polymorphic microsatellite markers: A8, A24, A29, A79, A88, A107, A113, B124, HbThe3 (Solignac et al. 2003; Solignac et al. 2007). All DNA extractions, PCR conditions, and genotype construction followed the same protocol as in the first experiment. The queen's genotype was reconstructed manually from her offspring drone's genotypes. We then compared the genotypes of the unmarked drones with those of the mother queen manually to exclude the possibility that they were from the focal colony, but had escaped being marked.

\section{RESULTS}

\subsection{Experiment 1: Drone flight distance of multiple feral colonies of unknown location}

We captured and genotyped 4343 drones, 2288 from transect $A$ and 2055 from transect B (Genotypes of individual drones are presented in supplementary tables S2.1 and $\mathrm{S} 2.2$.) The mean number of captured drones per site was $142 \pm 17.42$ s.e. (range 16-251). Following sibship reconstruction, 201 colonies contributed drones to the first transect and 231 to the second. Seven of the 30 sites had low sample size $(n<100)$, even though we sampled those sites 2-3 times. The number of inferred colonies at each site is presented in Table I.

In transect A, we discarded 174 of 201 families because they did not meet our criteria of large sample sizes (i.e. above the 90th percentile, $>22$ drones), leaving 27 families for further analysis (range 21-38 individuals/family). In transect B, we discarded 204 of the 231 colonies leaving 27 with a minimum 18 individuals per family (18-41 individuals/family) (Table I).

The average maximum distance between sites $(d)$ where the same colony was sampled is shown in Table II, together with the assumed flight distance, $r$, which is equal to $d / 2$ (Figure 2). These values may be underestimates 


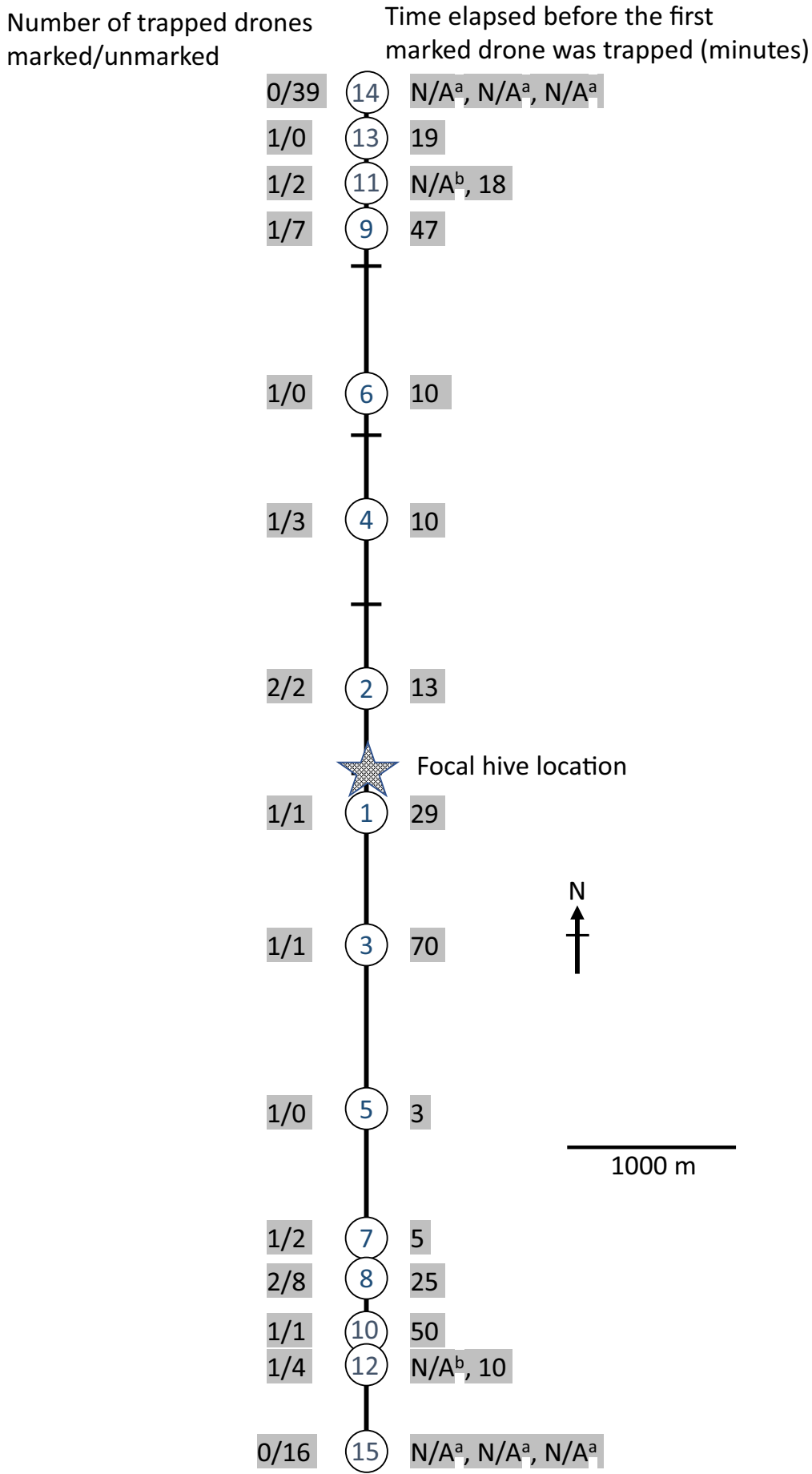

Figure 4. Number of marked drones and unmarked drones (left) and time when the first marked drone was trapped after the trap was launched (right). Superscript letter "a" indicates 150-min sampling time (all day) without catching any marked drones when the weather was clear. Superscript letter "b" indicates 150-min sampling time (all day) without catching any marked drones when the weather was overcast. Points 11 and 12 and points 14 and 15 were sampled on the same two and three consecutive days respectively. 
Table I. Number of inferred colonies from drones sampled from transects A and B

\begin{tabular}{|c|c|c|c|c|c|c|}
\hline \multicolumn{4}{|c|}{ Transect A } & \multicolumn{3}{|c|}{ Transect B } \\
\hline Site & $\begin{array}{l}\text { Sample } \\
\text { size }\end{array}$ & $\begin{array}{l}\text { Number of } \\
\text { families }^{1}\end{array}$ & $\begin{array}{l}\text { Number of family with } \geq \\
3 \text { members }^{2}\end{array}$ & $\begin{array}{l}\text { Sample } \\
\text { size }\end{array}$ & $\begin{array}{l}\text { Number of } \\
\text { families }^{1}\end{array}$ & $\begin{array}{l}\text { Number of families with } \\
\geq 3 \text { members }^{2}\end{array}$ \\
\hline 1 & 111 & 50 & 46 & 104 & 53 & 47 \\
\hline 2 & 121 & 66 & 61 & $59 *$ & $35^{*}$ & $32 *$ \\
\hline 3 & 251 & 85 & 78 & 212 & 73 & 71 \\
\hline 4 & 188 & 91 & 84 & 195 & 89 & 84 \\
\hline 5 & $58^{*}$ & $33^{*}$ & $32 *$ & 203 & 76 & 70 \\
\hline 6 & 217 & 87 & 83 & 124 & 70 & 69 \\
\hline 7 & 142 & 65 & 64 & $73 *$ & $52^{*}$ & $50^{*}$ \\
\hline 8 & 192 & 46 & 46 & $16^{*}$ & $15^{*}$ & $14^{*}$ \\
\hline 9 & 101 & 43 & 40 & $38^{*}$ & $17^{*}$ & $17^{*}$ \\
\hline 10 & 192 & 87 & 80 & 167 & 94 & 86 \\
\hline 11 & 190 & 85 & 84 & $22 *$ & $21^{*}$ & $20 *$ \\
\hline 12 & 132 & 68 & 63 & 216 & 103 & 94 \\
\hline 13 & $24 *$ & $20^{*}$ & $18^{*}$ & 194 & 61 & 57 \\
\hline 14 & 172 & 73 & 66 & 183 & 85 & 77 \\
\hline 15 & 197 & 69 & 65 & 167 & 82 & 74 \\
\hline Total & 2288 & 236 & 201 & 1973 & 265 & 231 \\
\hline
\end{tabular}

\footnotetext{
${ }^{1}$ Includes families with less than three males. This column is likely to be an overestimate of the actual number of colonies sampled

${ }^{2}$ Excludes families with less than three males. This may underestimate the actual number of families represented, since singleton males may indeed indicate a novel family

*Sample size below 100
}

of the true drone flight distance because most colonies were no doubt located off the transect and/or at one end of the transect. However, since one colony was detected at both ends of the 7-km transect A (Supplementary S1, Table II), we can infer that drones flew at least $3.5 \mathrm{~km}$ in this landscape.

\subsection{Experiment 2: Flight range of drone from a fixed location}

During suitable weather, marked drones were captured within 3 to $70 \mathrm{~min}$ of raising the trap aloft (Figure 4). No marked drones were captured $4.00 \mathrm{~km}$ from the colony in both directions, even

Table II. Flight distance of drones calculated from the transect data of experiment 1. Excludes all colonies below the 90th percentile

\begin{tabular}{lccll}
\hline Transect & Number of selected families & Mean flight distance $(r)(\mathrm{km})$ & SE & Maximum flight distance $(r)(\mathrm{km})$ \\
\hline A & 27 & 2.06 & 0.15 & 3.5 \\
B & 27 & 1.46 & 0.15 & 3.25 \\
Average & 54 & 1.76 & 0.11 & - \\
\hline
\end{tabular}


though 55 unpainted drones were trapped at the two sites over a total of 3 days per site, with $2.5 \mathrm{~h}$ of sampling each day. Microsatellite markers confirmed that all unmarked trapped drones did not belong to the focal colony (supplementary data S3).

\section{DISCUSSION}

\subsection{Estimated area from which honey bee drones fly to a trap}

We suggest that a $3.75-\mathrm{km}$ drone flight range is the appropriate value to use when estimating colony density from drones sampled in a Williams trap because this was the maximum distance we found painted males from our focal colony. This distance is congruent with observations from our first experiment. We found that drones from one colony were detected at sites $7 \mathrm{~km}$ apart. This indicates that drone flight range exceeds $7 / 2=3.5 \mathrm{~km}$. Based on a drone flight range of $3.75 \mathrm{~km}$, the area sampled by a Williams drone trap is $44 \mathrm{~km}^{2}$ and the number of colonies detected in a drone trap should be divided by 44 to obtain an estimate of the density of colonies in an ecosystem. This area is an order of magnitude greater than has been previously assumed (Moritz et al. 2007; Moritz et al. 2008; Jaffé et al. 2010) and suggests that previous estimates of colony density based on this technique are significant overestimates.

Note that we do not suggest that $3.75 \mathrm{~km}$ is the maximum distance that drones are able to fly, rather this is the typical distance sampled by a drone trap. This distance could vary due to the landscape and other biotic and abiotic factors. For example, Ruttner and Ruttner (1966) estimated that drones fly $2.3-3.0 \mathrm{~km}$ to a DCA. Ruttner and Ruttner (1972) showed that in mountainous country in Austria, where a > 1400-m-high mountain range forced drones to fly in one direction, drones flew up to $7 \mathrm{~km}$. We suggest that this situation was atypical, and that in a flat, homogenous landscape without a specific DCA, $3.75 \mathrm{~km}$ is the more probable drone flight range.

Since the true drone flight range $(3.75 \mathrm{~km})$ is considerably greater than that which has been previously assumed $(0.9 \mathrm{~km})$, we recommend that researchers should collect a very large number ( $>$ 300 ) of males at a site to ensure that all colonies in flight range are sampled. Large sample size has an additional benefit. Because the COLONY program uses maximum likelihood to assign drones to families, it is important to have multiple males per family. If a family is represented by only a few drones, COLONY may determine that two or more families are more likely than a single family for this group of brothers, because the genotype of the inferred mother is difficult to determine based on a small number of sons.

\subsection{Effects of the trap on drone mating flights}

The queen decoy has two properties that attract drones, a visual cue (a bouncing black object of queen shape and size) and the olfactory sex pheromone. The visual cue only acts over short distances (less than a few meters) and is only effective when drones are already present, attracted by queen pheromone, and the location (Gries and Koeniger 1996). Males can detect pheromone (9ODA) from at least $100 \mathrm{~m}$ (Brockmann et al. 2006), and possibly further if the trap is downwind of the source colony. This suggests the pheromone lure does not attract drones from beyond their normal flight range. However, even if it does, our estimate of drone flight range incorporates this effect, and is therefore appropriate distance to use when assessing the density of colonies using a drone trap.

\subsection{Estimated colony densities in south- central NSW}

We estimated honey bee colony densities in the Currawarna area based on an estimated $44 \mathrm{~km}^{2}$ sampling area by averaging colony density across sampling sites (Table III). We estimate that there were 1.47 colonies per $\mathrm{km}^{2}$ in transect $\mathrm{A}$ and 1.40 colonies per $\mathrm{km}^{2}$ in transect $\mathrm{B}$ based on the total number of colonies detected per site, but excluding families with fewer than 3 brothers. These density estimations are in the range of colony densities estimated by an agent-based model in Weddin Shire, also in southern NSW (Hinson et al. 2015). However, our estimate is subject to non-sampling error because our sampling sites were selected according to distance and 
not DCA characteristics. Only small numbers of drones could be caught at some sites (in some cases, less than 50 individuals), which we assume is because these sites were not suitable for the formation of drone aggregations or flyways.

We also estimated the density of colonies across sites combined, based on the $44 \mathrm{~km}^{2}$ radius flight range assumption per site (Table IV). Each transect samples an area of $86.48 \mathrm{~km}^{2}$ (Figure 5b). The estimated densities (transect A 2.32, transect B 2.67 colonies per $\mathrm{km}^{2}$ ) are ca. $50 \%$ higher than when drones from each sampling site were analysed separately. This suggests that the precision of estimates will be increased if several sites are used, and only sites where it is easy to catch drones are used. Using sites where the sample size is low causes an underestimate in colony density.

\subsection{Mating biology of honey bees}

Honey bees are extremely polyandrous (Palmer and Oldroyd 2000; Tarpy et al. 2004), and their mating behaviour captures the maximum genetic diversity available in the population (Baudry et al. 1998; Ding et al. 2017). High levels of intra-colonial genetic diversity are thought to contribute to colony fitness by enhancing the task allocation system (Mattila and Seeley 2007; Oldroyd and Fewell 2007), improving disease resistance (Seeley and Tarpy 2007) and reducing the proportion of diploid males (Page 1980). The ability of drones to fly more than $3.5 \mathrm{~km}$ from their colonies to congregate at DCAs undoubtedly helps to maximise intra-colonial diversity and panmixis.

\subsection{Practical significance of our findings for bee breeders and queen producers}

Our study shows that bee breeders who attempt to control honey bee mating by isolation need to locate their mating nuclei more than $3.75 \mathrm{~km}$ from the nearest colonies they wish to avoid. Since virgin queens also fly from their colony to mate, it is probably prudent to allow a buffer of $7.5 \mathrm{~km}$, when the mating distance of queens is conservatively assumed to be equal to drone mating flight distance. However, virgin queens likely fly 
Table IV. Colony densities in transects A and B when estimated by average density from each site and based on the whole transect

\begin{tabular}{llcc}
\hline Transect & Family selection & \multicolumn{2}{c}{ Density $\left(\right.$ colonies $\left./ \mathrm{km}^{2}\right)$} \\
\cline { 3 - 4 } & & Average per sample site & Based on the whole transect \\
\hline A & All families & 1.47 & 2.73 \\
& Families with $n \geq 3$ & 1.38 & 2.32 \\
B & All families & 1.40 & 3.06 \\
& Families with $n \geq 3$ & 1.31 & 2.67 \\
\hline
\end{tabular}

much further than drones, especially if they are unable to find males close to their colony. Peer (1957) showed that in northern Alberta, some queens successfully mated even when the nearest colonies carrying males were up to $16.2 \mathrm{~km}$ from their colony. However, successful mating was delayed relative to queens that were located nearer to drone source colonies, suggesting that queens only search for males at great distances if they cannot initially locate them. Therefore, if the colonies that the breeder wishes to use as drone source colonies are located near the mating nuclei, and there are no undesired drones within $7.5 \mathrm{~km}$, breeders should be able to obtain good control of matings under most circumstances. This conjecture supported empirical findings in England where $90 \%$ of matings occurred between colonies less than $7.5 \mathrm{~km}$ apart (Jensen et al. 2005).

If the goal is only to provide enough drones to ensure adequate mating frequency (Chapman

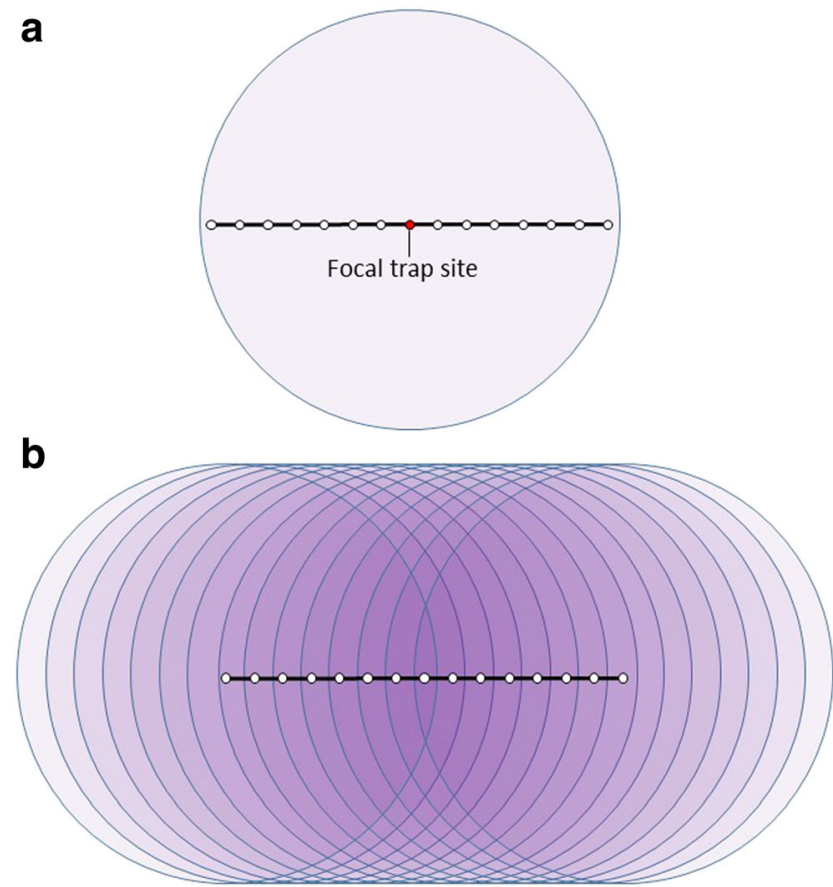

Figure 5. a Area sampled by a single trap. b Area sampled across all sites collectively. 
et al. 2019), drone source colonies should be presented within $3 \mathrm{~km}$ of the mating nuclei.

\subsection{Concluding remarks}

In agreement with previous studies (Ruttner and Ruttner 1966; Koeniger et al. 2005), our study shows that the normal drone flight range is $3.75 \mathrm{~km}$, and that therefore the area sampled by a single trap is $44 \mathrm{~km}^{2}$. We have determined this distance using a linear transect in two directions from a focal colony (experiment 2), and verified it by showing that drones from the same unknown colony can be detected across a distance of $7 \mathrm{~km}$ (experiment 1). Experiment 1 provides further information about the distribution of colonies in an environment, based on the drones they produce. Readers may use the data from experiment 1 to argue for a different sampling area should they wish to do so. For example, one can make a coherent argument that the average maximum distance that males were sampled across the top 90 percentile colonies in experiment 1 is more appropriate than the maximum distance (Moritz et al. 2007; Jaffé et al. 2010). However, because drones can be caught up to $3.75 \mathrm{~km}$ from their colony, we suggest that averaging across colonies will underestimate the true flight range, as illustrated in Figure 2.

\section{ACKNOWLEDGEMENTS}

We thank Frank Malfroy and Jenny Douglas for a very nice dinner and extraordinary logistical help and advice at the Lyndhurst site. Madeleine Beekman helped with drone trapping. Lea Ubdulkhalek helped with sample processing.

Estimation de la densité des colonies d'abeilles (Apis mellifera ) à l'aide de mâles piégés: superficie échantillonnée et distance du vol nuptialdistance de vol des mâles / densité des colonies / comportement d'accouplement / abeille sauvage

Abschätzen der Dichte von Bienenvölkern (Apis mellifera) durch das Fangen von Drohnen: Sammelfläche und Länge des Begattungsfuges Drohnen-Flugradius/ Bienenvolkdichte / Begattungsverhalten / wildlebende Honigbienen

\section{FUNDING INFORMATION}

This project was financially supported by AgriFutures Australia, though funding from the Australian Government Department of Agriculture as part of its Rural R\&D for Profit program, with further support from Horticulture Innovation Australia, the Almond Board of Australia, Lucerne Australia, Costa Group, and Raspberries and Blackberries Australia.

\section{REFERENCES}

Allen M.D. (1963) Drone production in honey-bee colonies (Apis mellifera L.). Nature 199 (4895): 789-790.

Arundel J., B.P. Oldroyd, S. Winter. (2012) Modelling honey bee queen mating as a measure of feral colony density. Ecol. Model. 247 : 48-57.

Arundel J., B.P. Oldroyd, S. Winter. (2013) Modelling estimates of honey bee (Apis spp.) colony density from drones. Ecol. Model. 267: 1-10.

Bailey L., B.V. Ball. (1991) Honey bee pathology. Academic Press, London.

Baudry E., M. Solignac, L. Garnery, M. Gries, J.M. Cornuet, et al. (1998) Relatedness among honeybees (Apis mellifera) of a drone congregation. Proc. R. Soc. Lond. B Biol. Sci. 265 (1409): 2009-2014.

Brockmann A., D. Dietz, J. Spaethe, J. Tautz. (2006) Beyond 9-ODA: sex pheromone communication in the european honey bee Apis mellifera L. J. Chem. Ecol. 32 (3): 657-667.

Butler C.G., R.K. Callow, N.C. Johnston. (1962) The isolation and synthesis of queen substance, 9-oxodectrans-2-enoic acid, a honeybee pheromone. Proc. R. Soc. Lond. B Biol. Sci. 155 (960): 417-432.

Butz Huryn V.M., M. Henrik. (1995) An assessment of the contribution of honey bees (Apis mellifera) to weed reproduction in New Zealand protected natural areas. N. Z. J. Ecol. 19: 111-122.

Chapman N.C., R. Dos Santos Cocenza, B. Blanchard, L.M. Nguyen, J. Lim, et al. (2019) Genetic diversity in the progeny of commercial Australian queen honey bees (Hymenoptera: Apidae) produced in autumn and early spring. J. Econ. Entomol. 112 (1):33-39.

Crane E. (1990) Bees and beekeeping: science, practice, and world resources. Cornell University Press, Ithaca, N.Y.

Cunningham S.A., F. FitzGibbon, T.A. Heard. (2002) The future of pollinators for Australian agriculture. Aust. J. Agric. Res. 53 (8): 893-900.

Cunningham S.A., A. Fournier, M.J. Neave, D. Le Feuvre, T. Diekötter. (2016) Improving spatial arrangement of honeybee colonies to avoid pollination shortfall and depressed fruit set. J. Appl. Ecol. 53 (2): 350-359. 
Currie R.W. (1987) The biology and behaviour of drones. Bee World 68 (3): 129-143.

Dick C.W. (2001) Genetic rescue of remnant tropical trees by an alien pollinator. Proc. Roy. Soc. B. 268 (1483): 2391-2396.

Ding G., H. Xu, B.P. Oldroyd, R.S. Gloag. (2017) Extreme polyandry aids the establishment of invasive populations of a social insect. Heredity 119 (5): 381-387.

Gary N.E. (1962) Chemical mating attractants in the queen honey bee. Science 136 (3518): 773-774.

Goulson D. (2003) Effects of introduced bees on native ecosystems. Annu. Rev. Ecol. Evol. Syst. 34 (1): 1-26.

Gries M., N. Koeniger. (1996) Straight forward to the queen: pursuing honeybee drones (Apis mellifera L.) adjust their body axis to the direction of the queen. $\mathrm{J}$. Comp. Physiol., A 179 (4): 539-544.

Gross C. (2001) The effect of introduced honeybees on native bee visitation and fruit-set in Dillwynia juniperina (Fabaceae) in a fragmented ecosystem. Biol. Cons. 102 (1): 89-95.

Gross C.L., D. Mackay. (1998) Honeybees reduce fitness in the pioneer shrub Melastoma affine (Melastomataceae). Biol. Cons. 86 (2): 169-178.

Hanley M.E., M. Franco, S. Pichon, B. Darvill, D. Goulson. (2008) Breeding system, pollinator choice and variation in pollen quality in British herbaceous plants. Funct. Ecol. 22 (4): 592-598.

Hansen D.M., J.M. Olesen, C.G. Jones. (2002) Trees, birds and bees in Mauritius: exploitative competition between introduced honey bees and endemic nectarivorous birds? J. Biogeogr. 29 (5/6): 721-734.

Hinson E.M., M. Duncan, J. Lim, J. Arundel, B.P. Oldroyd. (2015) The density of feral honey bee (Apis mellifera) colonies in South East Australia is greater in undisturbed than in disturbed habitats. Apidologie 46(3): 403-413.

Jaffé R., V. Dietemann, M.H. Allsopp, C. Costa, R.M. Crewe, et al. (2010) Estimating the density of honeybee colonies across their natural range to fill the gap in pollinator decline censuses. Conserv. Biol. 24 (2): 583-593.

Jensen A.B., K.A. Palmer, N. Chaline, N.E. Raine, A. Tofilski, et al. (2005) Quantifying honey bee mating range and isolation in semi-isolated valleys by DNA microsatellite paternity analysis. Conserv. Genet. 6 (4): 527-537.

Klein A.-M., I. Steffan-Dewenter, T. Tscharntke. (2003) Bee pollination and fruit set of Coffea arabica and C. canephora (Rubiaceae). Am. J Bot. 90 (1): 153-157.

Klein A.-M., B.E. Vaissière, J.H. Cane, I. SteffanDewenter, S.A. Cunningham, et al. (2007) Importance of pollinators in changing landscapes for world crops. Proc. Roy. Soc. B. 274 (1608): 303-313.

Koeniger G. (1990) The role of the mating sign in honey bees, Apis mellifera L.: does it hinder or promote multiple mating? Anim. Behav. 39 (3): 444-449.
Koeniger N., G. Koeniger, H. Pechhacker. (2005) The nearer the better? Drones (Apis mellifera) prefer nearer drone congregation areas. Insectes. Soc. 52 (1): 31-35.

Loper G.M., W.W. Wolf, O.R. Taylor. (1987) Detection and mornitoring of honeybee drone congregration areas by radar. Apidologie 18 (2): 163-172.

Loper G.M., W.W. Wolf, O.R. Taylor. (1992) Honey bee drone flyways and congregation areas: radar observations. J. Kans. Entomol. Soc. 65 (3): 223-230.

Magrach A., J.P. Gonzalez-Varo, M. Boiffier, M. Vila, I. Bartomeus. (2017) Honeybee spillover reshuffles pollinator diets and affects plant reproductive success. Nat. Ecol. Evol. 1 (9): 1299-1307.

Mattila H.R., T.D. Seeley. (2007) Genetic diversity in honey bee colonies enhances productivity and fitness. Science 317 (5836): 362-364.

Moritz R.F.A., V. Dietemann, R. Crewe. (2008) Determining colony densities in wild honeybee populations (Apis mellifera) with linked microsatellite DNA markers. J. Insect Conserv. 12 (5): 455-459.

Moritz R.F.A., S. Härtel, P. Neumann. (2005) Global invasions of the western honeybee (Apis mellifera) and the consequences for biodiversity. Ecoscience 12 (3): 289301.

Moritz R.F.A., F.B. Kraus, A. Huth-Schwarz, S. Wolf, C.A.C. Carrillo, et al. (2013) Number of honeybee colonies in areas with high and low beekeeping activity in Southern Mexico. Apidologie 44 (1): 113-120.

Moritz R.F.A., F.B. Kraus, P. Kryger, R.M. Crewe. (2007) The size of wild honeybee populations (Apis mellifera ) and its implications for the conservation of honeybees. J. Insect Conserv. 11 (4): 391-397.

Morse R.A., R. Nowogrodzki. (1990) Honey bee pests, predators, and diseases. Cornell University Press, Ithaca.

Oertel E. (1956) Observations on the flight of drone honey bees. Ann. Entomol. Soc. Am. 49 (5): 497-500.

Oldroyd B.P., J.H. Fewell. (2007) Genetic diversity promotes homeostasis in insect colonies. Trends Ecol. Evol. 22 (8): 408-413.

Oldroyd B.P., S. Lawler, R.H. Crozier. (1994) Do feral honey bees (Apis mellifera) and regent parrots (Polytelis anthopeplus ) compete for nest sites? Austral Ecol. 19(4): 444-450.

Oldroyd B.P., E.G. Thexton, S.H. Lawler, R.H. Crozier. (1997) Population demography of Australian feral bees (Apis mellifera). Oecologia 111 (3): 381-387.

Page R.E. (1980) The evolution of multiple maiting behaviour by honey bee queens (Apis mellifera $\mathrm{L}$.). Genetics 96 (1): 263-273.

Page R.E., C.Y.S. Peng. (2001) Aging and development in social insects with emphasis on the honey bee, Apis mellifera L. Exp. Gerontol. 36 (4): 695-711.

Palmer K.A., B.P. Oldroyd. (2000) Evolution of multiple mating in the genus Apis. Apidologie 31 (2): 235-248. 
Paton D.C. (1993) Honeybees in the Australian environment. Bioscience 43 (2): 95-103.

Paton D.C. (1996) Overview of feral and managed honeybees in Australia, Canberra.

Peer D. (1957) Further studies on the mating range of the honey bee, Apis mellifera L. Can. Entomol. 89 (3): 108-110.

Rinderer T.E., B.P. Oldroyd, S. Wongsiri, H.A. Sylvester, L.I.D. Guzman, et al. (1993) Time of drone flight in four honey bee species in south-eastern Thailand. J. Apic. Res. 32 (1): 27-33.

Ruttner F. (1988) Biogeography and taxonomy of honeybees. Springer Science \& Business Media, Berlin, Germany.

Ruttner F., H. Ruttner. (1966) Untersuchungen über die Flugaktivität und das Paarungsverhalten der Drohnen. III.-Flugweite und Flugrichtung der Drohnen. Z. Bienenforsch. 8 : 332-354.

Ruttner H. (1974) Drohnensammelplätze ein beispiel von paarungsverhalten bei Insekten. Anz. Schälingskde. Pflanzen-Umweltschutz 47 : 39-42.

Ruttner H. (1976) Untersuchungen über die flugaktivität und das paarungsverhalten der drohnen. VI.-Flug auf und über höhenrücken. Apidologie 7 (4): 331-341.

Ruttner H., F. Ruttner. (1972) Untersuchungen über die flugaktivität und das paarungsverhalten der drohnen. V.-Drohnensammelplätze und paarungsdistanz. Apidologie 3 (3): 203-232.

Saunders D.A., G.T. Smith, I. Rowley. (1982) The availability and dimensions of tree hollows that provide nest sites for cockatoos (Psttaciformes) in Western Australia. Aust. J. Wildl. 9 : 541-546.

Seeley T.D. (2016) Following the wild bees: the craft and science of bee hunting. Princeton University Press, Princeton and Oxford.

Seeley T.D., D.R. Tarpy. (2007) Queen promiscuity lowers disease within honeybee colonies. Proc. Roy. Soc. B. 274 (1606): 67-72.

Simpson S., C. Gross, L. Silberbauer. (2005) Broom and honeybees in Australia: an alien liaison. Plant Biol. 7 (5): 541-548.

Solignac M., F. Mougel, D. Vautrin, M. Monnerot, J.-M. Cornuet. (2007) A third-generation microsatellitebased linkage map of the honey bee, Apis mellifera, and its comparison with the sequence-based physical map. Genome Biol. 8(4): R66.

Solignac M., D. Vautrin, A. Loiseau, F. Mougel, E. Baudry, et al. (2003) Five hundred and fifty microsatellite markers for the study of the honeybee (Apis mellifera L.) genome. Mol. Ecol Notes 3 (2): 307-311.
Spira T.P. (2001) Plant-pollinator interactions: a threatened mutualism with implications for the ecology and management of rare plants. Nat. Areas J. 21 (1): 78-88.

Szabo T.L. (1995) The production of drone comb and drone brood in honey bee colonies, Dadant \& Sons, Hamilton, pp. 642-643.

Taber R.D.S. (1964) Factors influencing the circadian flight rhythm of drone honey bees. Ann. Entomol. Soc. Am. 57 (6): 769-775.

Tarpy D.R., R. Nielsen, D.I. Nielsen. (2004) A scientific note on the revised estimates of effective paternity frequency in Apis. Insectes. Soc. 51 (2): 203-204.

Taylor O.R., G.A. Rowell. (1988) Drone abundance, queen flight distance, and the neutral mating model for the honey bee, Apis mellifera, Africanized honey bees and bee mites., Ellis Horwood, Chichester, UK, pp. 173-183.

Utaipanon P., T.M. Schaerf, B.P. Oldroyd. (2019) Assessing the density of honey bee colonies at scales. Ecol. Entomol. 44 :291-304.

Walsh P.S., D.A. Metzger, R. Higuchi. (1991) Chelex 100 as a medium for simple extraction of DNA for PCRbased typing from forensic material. BioTechniques 10 (4): 506-513.

Wang J. (2004) Sibship reconstruction from genetic data with typing errors. Genetics 166(4): 1963-1979.

Wang J. (2013) An improvement on the maximum likelihood reconstruction of pedigrees from marker data. Heredity 111 (2): 165.

Wenner A.M. (1989) Bee-lining and ecological research on Santa-cruz island, Dadant \& Sons, Hamilton, pp. 808809.

Williams J.L. (1987) Wind-directed pheromone trap for drone honey-bees (Hymenoptera, Apidae). J. Econ. Entomol. 80 (2): 532-536.

Winston M.L. (1991) The biology of the honey bee. Harvard University Press, Cambridge, Mass.

Winston M.L. (1992) Killer bees: The Africanized honey bee in the Americas. Harvard University Press, Cambridge, Mass.

Wood M.S., R.L. Wallis. (1998) Potential competition for nest sites between feral European honeybees (Apis mellifera) and common brushtail possums (Trichosurus vulpecula). Aust. Mammal. 20 : 377-388.

Publisher's note Springer Nature remains neutral with regard to jurisdictional claims in published maps and institutional affiliations. 